\title{
GROSS CALCIFICATION OF THE MITRAL VALVE
}

\author{
BY \\ ALLAN WYNN \\ From the Cardiac Department, St. Thomas's Hospital* \\ Received March 12, 1952
}

Some degree of calcification of the mitral valve is a common finding at autopsy in advanced rheumatic heart disease. Epstein (1940) reported its presence in 64 out of 148 consecutive postmortem examinations in amounts varying from that detectable only by microscopy to large calcareous masses. Although the valve leaflets were most often affected, the annulus fibrosus, the chordæ tendineæ, the papillary muscles, and the wall of the left auricle may also be involved. Sometimes gross calcification was confined to only one of these sites, the annulus fibrosus alone being particularly affected in elderly patients with mitral stenosis. With the exception of this group, the degree of calcification tended to correspond with the severity of the other changes due to the rheumatic process.

\section{Present InVestigation AND Methods}

Because of the renewed interest in mitral valvulotomy, it is of some practical importance to consider the clinical features that accompany gross mitral valve calcification, particularly its relation to the duration and severity of the disease, its effects upon the sounds and murmurs, and upon the competence of the mitral valves. These features have been studied in 60 adult patients with mitral stenosis, and evidence of gross valvular calcification. This was defined as a degree of calcification sufficient to be seen by fluoroscopic examination or the presence of craggy masses of calcareous material in the mitral valve at necropsy or at mitral valvulotomy. Calcareous plaques, too small to be seen by fluoroscopy, were sometimes found at valvulotomy or at necropsy. It was considered that these were unlikely to modify the physical signs or alter the function of the mitral valves, so such patients were not included in the grossly calcified group.

One hundred and seventy patients with mitral stenosis without radiological evidence of mitral calcification served as controls. The patients without calcification were unselected; some of those with calcification were specially referred. Patients with aortic stenosis, severe aortic incompetence, hypertension, acute rheumatic carditis, and bacterial endocarditis were excluded.

Clinical and fluoroscopic examinations were performed by the author, and when mitral calcification was considered to be present, and in many of the remainder, an independent fluoroscopic examination was made. Phonocardiograms were taken in many patients, especially when the findings on auscultation were in doubt. In some of the patients, hæmodynamic data obtained by cardiac catheterization and at mitral valvulotomy were available. The technique used for obtaining left auricular pressures at operation has been detailed elsewhere (Wynn et. al., 1952).

Fifty-eight patients had radiological evidence of mitral calcification. In twelve, this was also proven at valvulotomy, and in six at necropsy. Two patients with gross mitral calcification at necropsy were not examined radiologically.

In the 170 patients in whom there was no radiological evidence of mitral calcification, the mitral valve was examined at valvulotomy in thirty-four, and at necropsy in eight. Calcification in these patients was absent or limited to microscopic infiltration or to small plaques.

* This work was started at the Postgraduate Medical School of London. 


\section{RESULTS}

Age Incidence of Gross Mitral Calcification

The age incidence in decades from 15-75 years is shown in Fig. 1. In the three decades up to forty-five there was a slight preponderance of patients without gross calcification. This was reversed in the three decades after forty-five, but the difference is too slight to suggest that the severity of calcification is closely related to age or to the duration of the disease. Seven patients with gross mitral calcification were under 25 years, the youngest being a girl aged 18 years. The extent to which it may be present in the young is shown by the radiological appearances in a man of 26 years (Fig. 2), and the necropsy appearance in a woman of 28 years (Fig. 3).

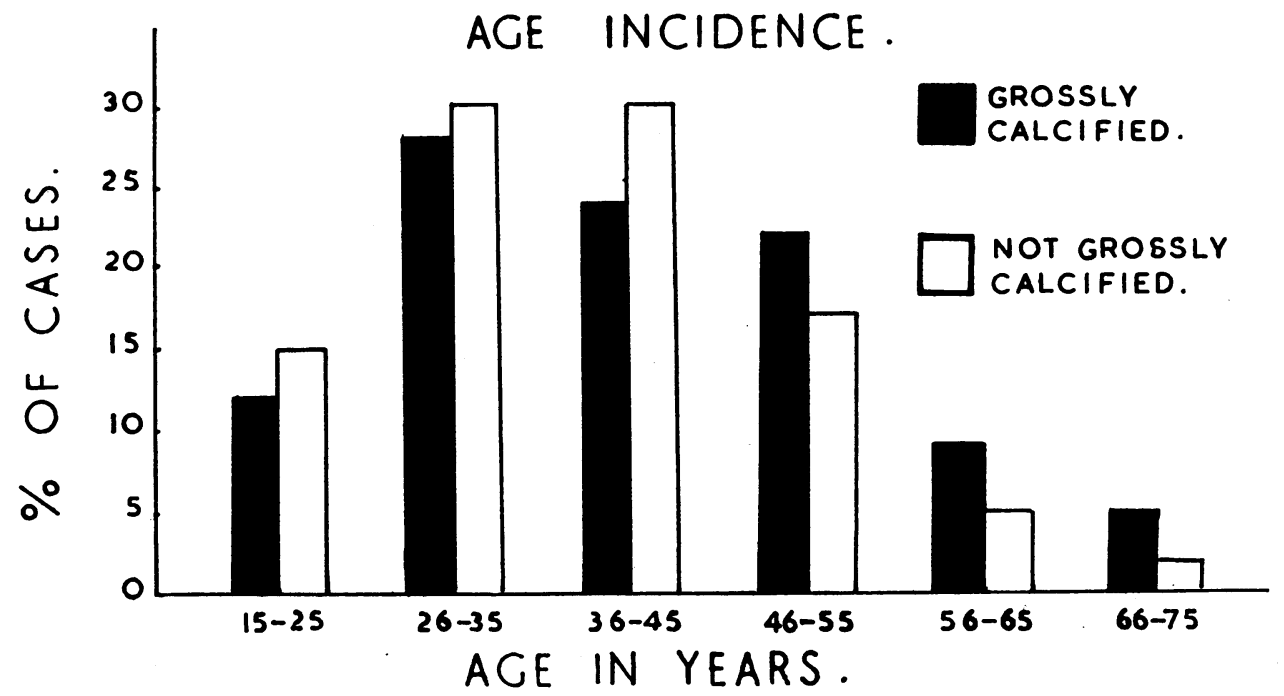

Fig. 1.-Shows age incidence of gross mitral valve calcification in decades from 15 to 75 years of age.

\section{Relation of Mitral Calcification to Clinical Severity}

To assess the clinical severity, the patients were divided into three grades, using the following criteria.

Grade I.-Patients with no symptoms, or with symptoms only on more than ordinary effort.

Grade II.-Patients able to work normally despite symptoms produced by ordinary activities.

Grade III.-Patients with symptoms at rest or on slight effort, and unable to work or else capable of only light tasks.

Of the patients with gross mitral calcification 15 per cent had only mild symptoms compared with 35 per cent of the control group. Of the former 38 per cent had symptoms of Grade II severity compared with 33 per cent of the control group.

In patients with gross calcification 47 per cent had symptoms of Grade III severity compared with 32 per cent in the control group.

The proportion of patients with severe symptoms in both groups is unduly high because many had been referred for assessment of their suitability for mitral valvulotomy. That 9 patients with gross mitral calcification had few symptoms and more than half were working normally indicates that this process does not closely parallel the clinical severity of the disease.

\section{Hamodynamic Data}

The pulmonary artery and "pulmonary capillary" pressures at rest and after exercise were obtained by cardiac catheterization in all the patients operated upon, and in many of the remaining patients of Grade II and III severity in both groups. The details of this investigation will be presented in a separate communication. There was no significant difference between either pulmonary artery or " pulmonary capillary" 


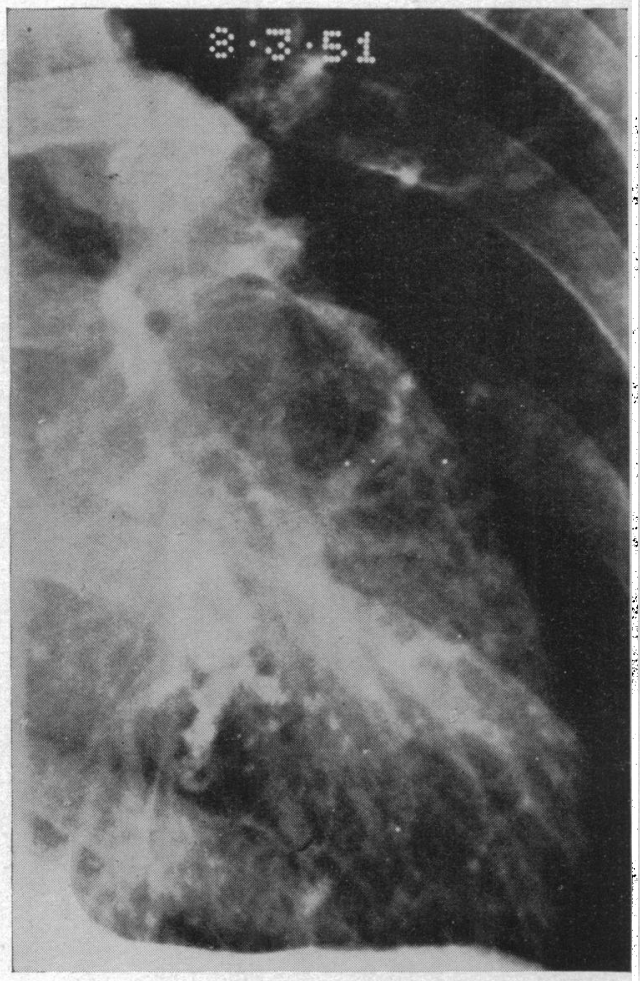

FIG. 2.-Penetrating film in right anterior oblique position to show extensive calcification in the mitral valve in a man of 26 years.

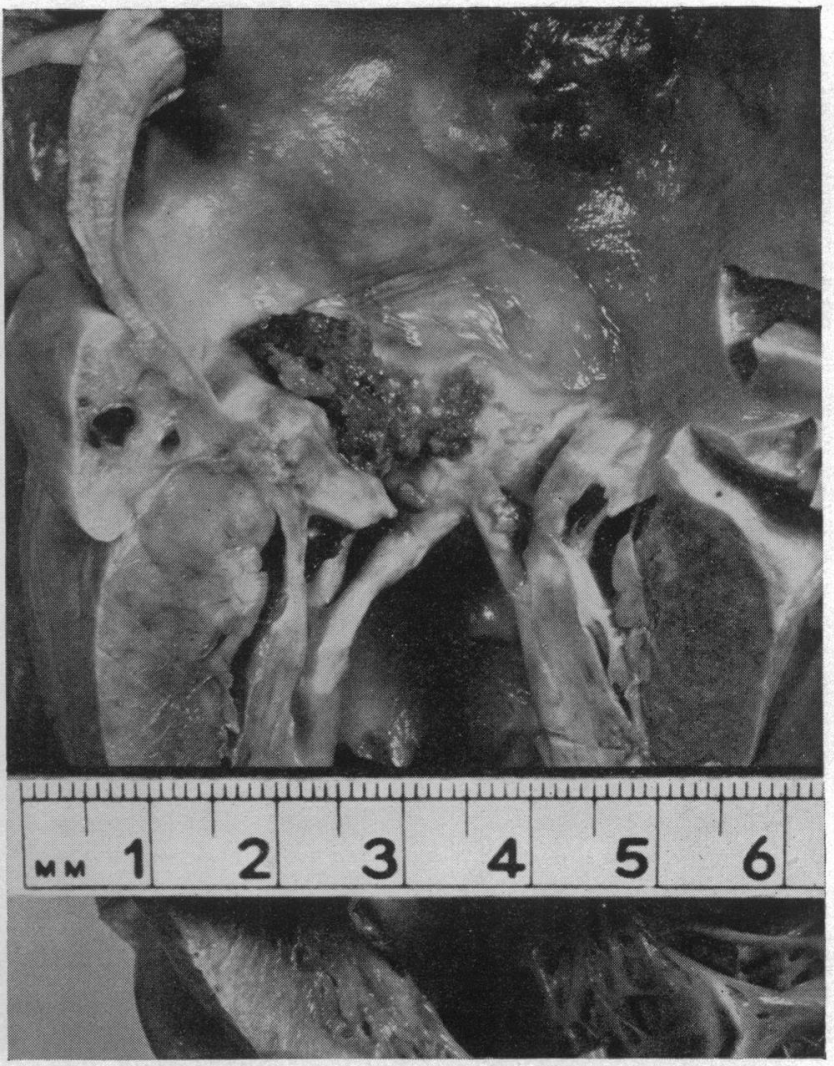

FIG. 3.-Gross calcification in the mitral valve extending on to the chordx tendineae in a woman of 28 years, with mitral stenosis, who died in cardiac failure. The absence of left ventricular dilatation or hypertrophy suggests that there was no significant mitral reflux in life.

pressures in the two groups. The only noteworthy feature was the demonstration in 4 patients with gross mitral calcification of mean pulmonary artery pressures at rest of $25 \mathrm{~mm}$. Hg or less, which supports the view previously derived clinically that gross mitral calcification may occur in the absence of severe mitral stenosis.

\section{Effect of Gross Calcification on Sounds and Murmurs}

The combination of a loud first heart sound, a widely duplicated second sound, a rumbling diastolic murmur and no systolic murmer is well called the mitral rhythm of Duroziez, following this author's classical description in 1862 (Fig. 4). Later, Potain stated that this rhythm was typical of only the middle phase of mitral stenosis when the valve cusps, although thickened and fibrous, were still flexible. If they became rigid and immobilized by calcification the first sound tended to be muffled, systolic murmurs appeared and were often loud, the "opening snap" disappeared and the low-pitched diastolic rumble was replaced by a high-pitched murmur.

The results reported below tend to confirm the accuracy of this observation.

(i) The First Heart Sound. As the character of the first heart sound in mitral stenosis is greatly modified by the heart rate, the patients were examined reclining and when the pulse rate was between 65 and 90 a minute. Observations were made on the loudness, quality, and palpability of the first heart sound at the apex. These were recorded before the fluoroscopic examination.

The first sound was called snapping when it was accentuated, rather high-pitched, and peremptory. The vibrations were usually palpable often over a localized area at or near the apex. A snapping first sound occurred in 20 per cent of the patients with gross calcification and in 50 per cent of the controls (Table I).

A loud, but dull or blurred, first sound, whose vibrations were much less frequently palpable - and then 
often over a diffuse area of the pracordium-was heard in 35 per cent of the calcified group, and in 32 per cent of the uncalcified group. Whether loud or snapping, the first sound was palpable in 33 per cent of the calcified group compared with 68 per cent of the controls.

The first sound was normal or obscured by a systolic murmur in 45 per cent of the patients in the calcified group and in 18 per cent of those without evidence of gross valvular calcification. With tachycardia, however, the first sound was frequently loud, sharp, and readily palpable in many of the patients with mitral calcification.

(ii) Systolic Murmurs. Systolic murmurs at the apex were graded according to intensity as faint, medium, and loud (Table I). These were twice as frequent in the calcified group, and were more often loud. Nevertheless, one in five patients with gross valvular calcification had no systolic murmur. In one patient

TABLE I

Comparison of Physical Signs Produced by Calcified and Uncalcified Valves

\begin{tabular}{|c|c|c|c|c|c|c|c|c|c|c|c|}
\hline \multirow[b]{3}{*}{ Calcified } & \multirow[b]{3}{*}{.. } & \multirow[b]{3}{*}{.. } & \multicolumn{4}{|c|}{$\begin{array}{c}\text { First heart sound } \\
(\%)\end{array}$} & \multicolumn{4}{|c|}{$\begin{array}{c}\text { Mitral systolic murmurs } \\
(\%)\end{array}$} & \multirow{2}{*}{$\begin{array}{c}\text { Opening } \\
\text { snap } \\
(\%)\end{array}$} \\
\hline & & & Snapping & Loud & $\begin{array}{c}\text { Normal or } \\
\text { obscured }\end{array}$ & Palpable & Faint & Medium & Loud & Total & \\
\hline & & & 20 & 35 & 45 & 33 & 10 & 28 & 28 & 66 & 48 \\
\hline Uncalcified & .. & .. & 50 & 32 & 18 & 68 & 10 & 15 & 17 & 42 & 82 \\
\hline
\end{tabular}

without a systolic murmur both cusps of the mitral valve were found to be extensively calcified at necropsy, and there was a calcareous mass $10 \mathrm{~mm}$. in diameter extending from the base to the free margin of the postero-medial cusp.

(iii) The "Opening Snap." An added protodiastolic sound in the cardiac cycle which had most or all of the following features, was regarded as an "opening snap" (Wolferth and Margolies, 1932).

(a) Distinctly separate from the second sound even during expiration.

(b) Heard widely, but never loudest at the base.

(c) Loudest at a point between the apex and the left sternal border, but sometimes very well heard at the apex when the diastolic murmur was not loud or long.

(d) Often preceding the diastolic rumble by an audible gap.

(e) Often having a superficial clicking quality.

Clinical differentiation between a widely split second sound, an "opening snap," and a loud third heart sound was sometimes impossible. The phonocardiogram was then used to help in identification. When the interval between the two sounds was less than $0.06 \mathrm{sec}$., in the absence of right bundle branch block at pulse rates under 85 a minute, it was regarded as a split second sound. When the interval was between 0.06 and $0.12 \mathrm{sec}$. the added sound was classed as an "opening snap." With tachycardia the "opening snap " may approach as close as $0.05 \mathrm{sec}$. to the second sound, when it cannot be distinguished from a split sound due to asynchronous closure of the pulmonary and aortic valves. When the heart rate slows, however, or after an unduly long diastole if there is auricular fibrillation, the interval may increase to more than $0.06 \mathrm{sec}$. if the added sound originates in the mitral valve. In many cases, the difficulty of identification was resolved by recording both a split second sound and an "opening snap" in the same cycle (Fig. 5). This was possible more often when the record was taken in varying phases of respiration.

The jugular phlebogram was found to be a useful reference tracing in distinguishing between the "opening snap " and a third heart sound. The latter occurs after the peak of the "V" wave of the phlebogram and usually more than $0 \cdot 12 \mathrm{sec}$. after the second sound.

An "opening snap" was present on auscultation or clearly demonstrated by phonocardiography in 48 per cent of the calcified group compared with 82 per cent of the controls. In many of the control patients this sound had a sharp clicking quality, which was rarely present in the patients with gross mitral calcification. Although the mechanism of production of this sound is unknown, the evidence reviewed by Wolferth and Margolies (1932) that it is produced by the opening movement of the mitral valves is good. Its persistence in the presence of extensive calcification may be due to part of the valve cusps and chordæ tendineæ being uncalcified and flexible (Wolferth and Margolies, 1937). 


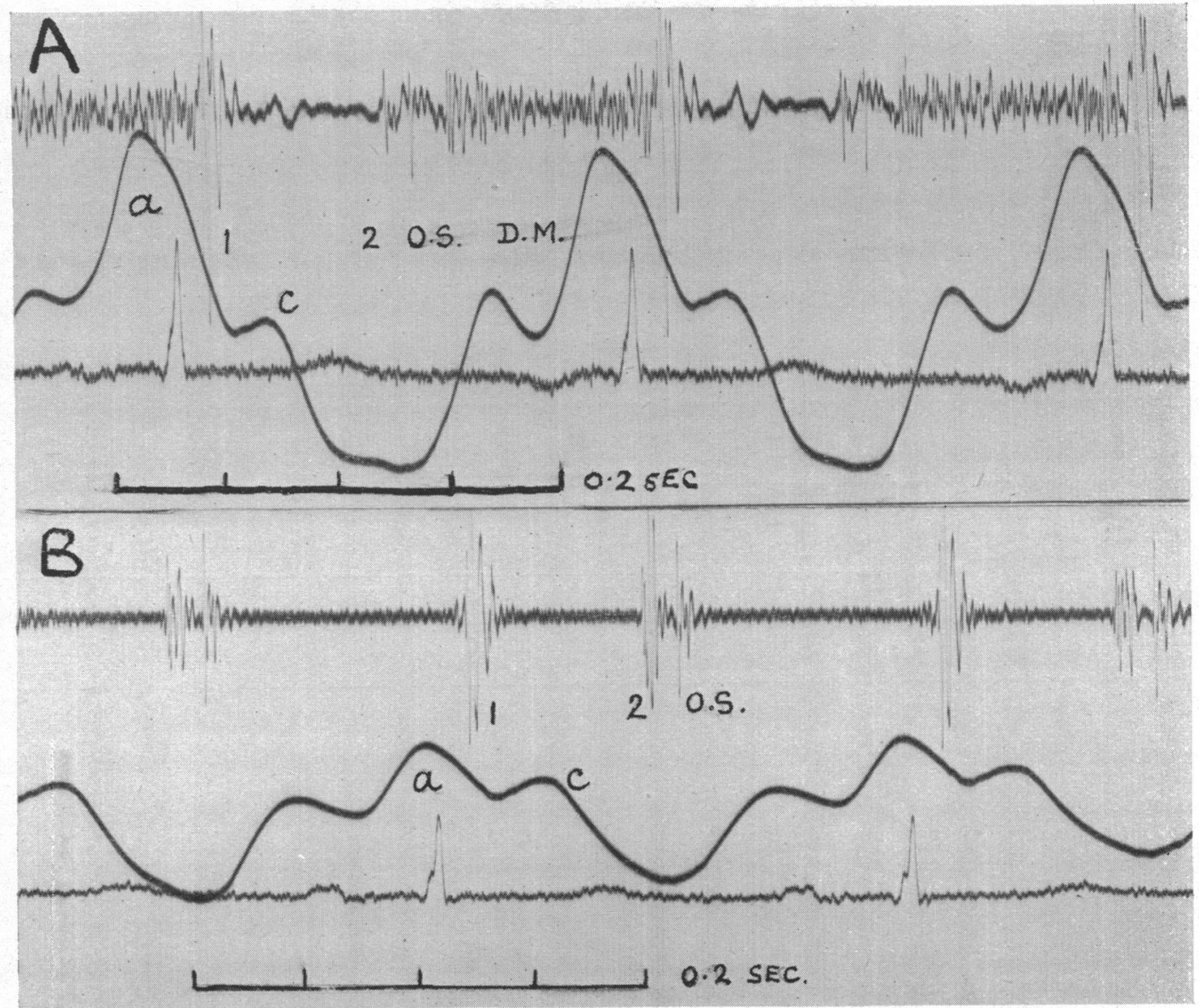

FIg. 4.-Rhythm of Duroziez in a patient with no valvular calcification at mitral valvulotomy, showing loud first sound, no systolic murmur, widely duplicated second sound, and rumbling diastolic murmur with mid and late diastolic accentuation. (A) phonocardiogram at apex. (B) phonocardiogram at left sternal border in fourth left intercostal space.
P.C. Phonocardiogram.
J.V.P. Jugular phlebogram.
E.C. Electrocardiogram.

(iv) The Diastolic Murmur. No difference in duration, intensity or pitch of the diastolic murmur could be detected between the two groups by the methods used in this investigation.

A pure rhythm of Duroziez was heard in 28 out of 42 patients who had little or no calcification at operation or at necropsy (Fig. 4); in 18 patients with gross calcification at operation or at necropsy it was present only three times. In one of these patients the calcified mass was confined to the annulus fibrosus, and in another the calcification was thought by the surgeon to involve mainly the floor of the auricle while the cusps themselves remained flexible.

\section{Effect of Calcification on the Incidence of Mitral Incompetence.}

No attempt was made to diagnose slight degrees of mitral incompetence in this study. It was considered, however, that significant mitral regurgitation in the presence of mitral stenosis could be detected by the following criteria.

(1) A mitral systolic murmur with clinical evidence of an enlarged or hyperdynamic left ventricle, shown by a localized, unduly forceful apex beat accompanied by enlargement of the left ventricle and left auricle on fluoroscopy. Patients with significant aortic valve disease or hypertension were excluded.

(2) In the absence of a characteristic apical impulse a diagnosis of left ventricular enlargement on fluoroscopy was made only when the enlargement appeared considerable. 


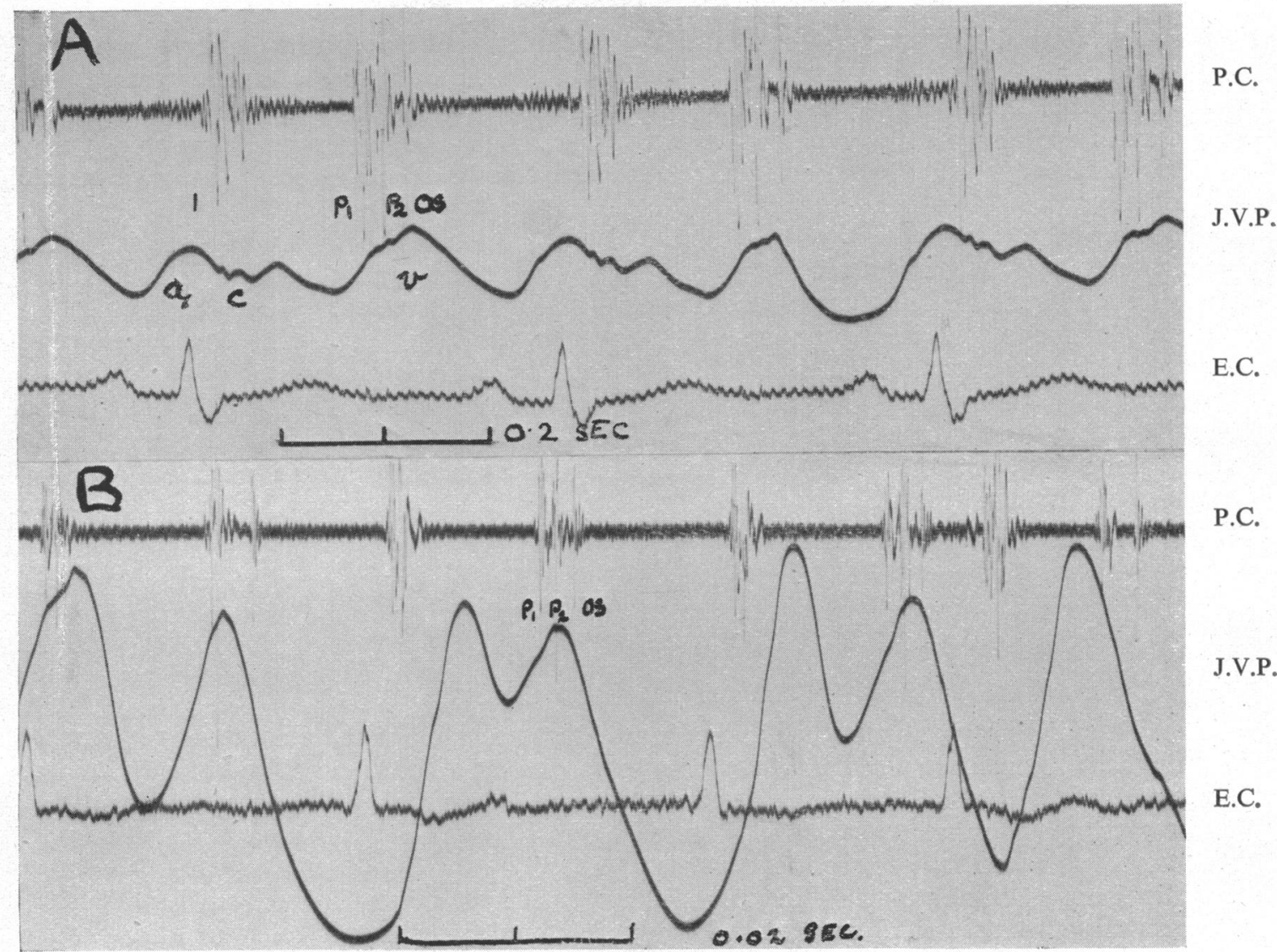

Fig. 5.-(A) Phonocardiogram showing a split second sound and an "opening snap" in each cardiac cycle. (B) Phonocardiogram showing phasic splitting of the second sound with an "opening snap." Phonocardiogram at left sternal border in fourth left intercostal space.

P.C. Phonocardiogram. J.V.P. Jugular phlebogram. E.C. Electrocardiogram.

(3) When the left auricle was very large or aneurysmal.

(4) Electrocardiographic evidence of left ventricular hypertrophy when it occurred.

Systolic expansion of the left auricle (Heim de Balsac et al., 1949), when it occurred in the absence of criteria already discussed, was not accepted as evidence of mitral incompetence. It is due presumably to the sharp rise in auricular pressure during ventricular systole, which can be frequently demonstrated at valvulotomy, especially if there is auricular fibrillation (Wynn et al., 1952).

Froment et al. (1950) suggest that systolic expansion of the left auricle is due to retropulsion of the mitral valve cone into the left auricle during ventricular contraction. Support for this view was obtained in the present study, for, on fluoroscopy in the right anterior oblique position, the movement of mitral calcification was frequently seen to be backwards and synchronous with the movements of the border of the left auricle during ventricular systole.

The incidence of mitral incompetence judged by the above criteria was 40 per cent in the calcified group and 21 per cent in the control group. More direct evidence that the mitral valves may be competent, although grossly calcified, was obtained at operation. In 12 patients with gross calcification at operation a regurgitant jet was felt in six, while in 34 of the control group a regurgitant jet was felt in eight patients.

The left auricular pressures obtained at operation were of more limited value than the surgeon's findings in demonstrating mitral incompetence (Wynn et al., 1952). Nevertheless, they supported the view that in half the patients with gross calcification of the valve there was no significant mitral incompetence. 


\section{DisCUSSION}

These results indicate that gross calcification of the mitral valve, occurring as a complication of rheumatic heart disease, has no striking connotations in either a clinical or hæmodynamic sense, except in relation to mitral regurgitation. Although occurring more frequently in the older age groups and in patients with severe symptoms, the differences were not great. Moreover, it may occur in young patients and in those with no clinical or hæmodynamic evidence of severe rheumatic heart disease.

When gross mitral calcification is present the classical auscultatory rhythm of Duroziez is not often heard, but to what extent this is due to associated factors such as reduced mitral blood flow, congestive cardiac failure, and mitral incompetence, it is difficult to say. When the calcification is largely confined to the region of the annulus fibrosus or to the floor of the auricle, leaving the mitral leaflets flexible, however, the rhythm of Duroziez may be present.

Although the true incidence of mitral incompetence is difficult to determine, the clinical and operative evidence in this survey suggests that significant mitral incompetence occurs in about half the patients with gross valvular calcification, being twice as frequent as in the controls. How closure of the mitral valves is achieved when the valve cusps and ring are grossly calcified is obscure. Lutembacher (1950) attributes a piston-like action to the hypertrophied papillary muscles which seals off the mitral orifice during ventricular systole. The observation that mitral calcification is thrust backwards into the auricle at the onset of ventricular contractions supports this view.

\section{Summary AND CONCLUSIONS}

The relation of gross valvular calcification in mitral stenosis to age and clinical severity, and its effect upon the auscultatory physical signs and upon the function of the mitral valves has been studied. There were 60 patients with gross mitral calcification and 170 controls.

The patients with gross mitral calcification were only slightly older, 86 per cent being under 55 years compared with 92 per cent of the controls.

Although more of the patients with gross calcification had clinical and hæmodynamic evidence of severe mitral valve disease, 15 per cent had only mild symptoms and over half were able to work normally.

In the presence of gross mitral calcification the first heart sound was rarely snapping or palpable at pulse rates under 90 a minute. In 80 per cent a mitral systolic murmur was present, and this was often loud. An opening snap was less often heard in these cases and was rarely loud or clicking, but the diastolic murmur appeared to be unaffected.

The diagnostic value of these observations is limited because of the many variables involved.

Significant mitral incompetence was thought to be twice as common in the patients with gross mitral calcification compared with the controls.

I would like to thank Prof. J. McMichael, Dr. J. F. Goodwin, Dr. Evan Jones, and Dr. R. Daley for their advice and encouragement and for permission to examine the cases in their charge. I am very grateful to Dr. R. E. Steiner who co-operated in the radiological studies of many of the cases.

\section{REFERENCES}

Duroziez, P. (1862). Arch. Gen. de Med., 20, 385.

Epstein, B. S. (1940). Arch. intern. Med., 65, 279.

Froment, R., Gonin, A., Gallavardin, L. (1950). Arch. Mal. Caur., 43, 678.

Heim de Balsac, R., Allesandris, L., Routier, D. (1949). Arch. Mal. Ceeur., 42, 525.

Lutembacher, R. (1950). Le Rétrécisement Mitral. Masson et Cie, Paris.

Potain, P. Clinique medicale de la Charite. Paris, 1894. Cited by Vaquez and Laidlow. Diseases of the Heart. London, 1924.

Wolferth, C. C., and Margolies, A. (1932). Amer. Heart J., 7, 443.

W (1937). Trans. Assoc. Amer. Phys., 52, 346.

Wynn, A., Matthews, M. B., McMillan, I. K. R., Daley, R. (1952). Lancet, $2,261$. 